\title{
Physical Activity Participation and Academic Performance Among Uitm Seremban Students
}

\author{
Hasyyati Husna Dzoolkarnain, Azman Ahmad Tajri, Siti Aida Lamat, Nur \\ Hani Syazwani Bakri
}

To Link this Article: http://dx.doi.org/10.6007/IJARBSS/v11-i11/11198

DOI:10.6007/IJARBSS/v11-i11/11198

Received: 03 September 2021, Revised: 01 October 2021, Accepted: 26 October 2021

Published Online: 08 November 2021

In-Text Citation: (Dzoolkarnain et al., 2021)

To Cite this Article: Dzoolkarnain, H. H., Tajri, A. A., Lamat, S. A., \& Bakri, N. H. S. (2021). Physical Activity Participation and Academic Performance Among Uitm Seremban Students. International Journal of Academic Research in Business and Social Sciences, 11(11), $372-380$.

Copyright: (c) 2021 The Author(s)

Published by Human Resource Management Academic Research Society (www.hrmars.com)

This article is published under the Creative Commons Attribution (CC BY 4.0) license. Anyone may reproduce, distribute, translate and create derivative works of this article (for both commercial and non-commercial purposes), subject to full attribution to the original publication and authors. The full terms of this license may be seen at: http://creativecommons.org/licences/by/4.0/legalcode

Vol. 11, No. 11, 2021, Pg. $372-380$

Full Terms \& Conditions of access and use can be found at http://hrmars.com/index.php/pages/detail/publication-ethics 


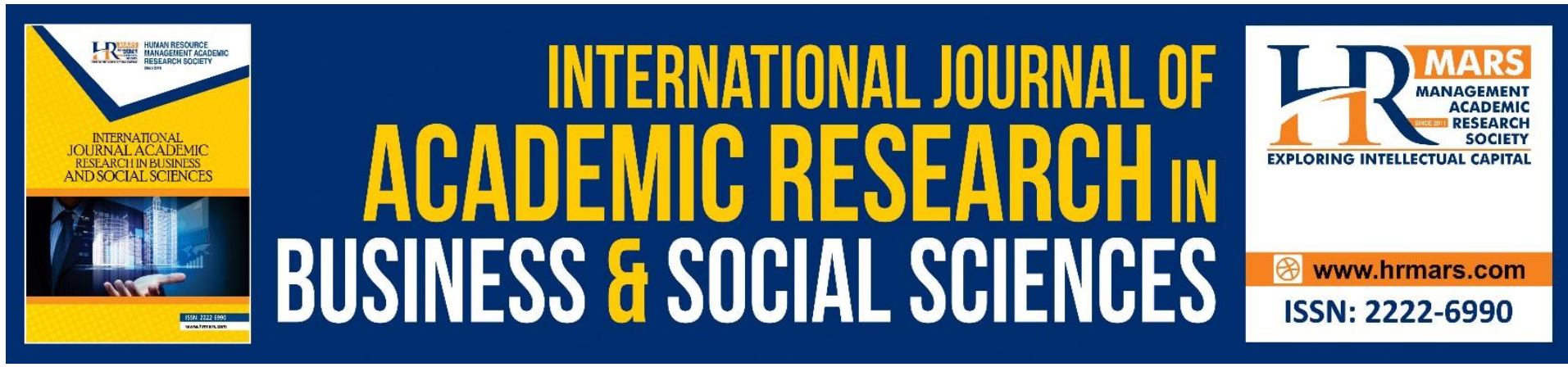

\title{
Physical Activity Participation and Academic Performance Among Uitm Seremban Students
}

\author{
Hasyyati Husna Dzoolkarnain, Azman Ahmad Tajri, Siti Aida \\ Lamat, Nur Hani Syazwani Bakri
}

Faculty of Sport Science and Recreation, Universiti Teknologi MARA, Cawangan Negeri Sembilan, Kampus Seremban

\begin{abstract}
This study exploits a quantitative approach in identifying the relationship between physical activity participation and academic performance among Universiti Teknologi MARA (UiTM) Seremban students. A total of 357 students consisting of 168 male and 189 female from all faculties in UiTM Seremban has been recorded and gathered. Descriptive analysis and Spearman's Correlation analysis have been used in determining the relationship between inactive, minimally active and HEPA active variables. This study used a stratified sampling method that consists of two sections $A$ and $B$. Section A for respondent demographic and section $B$ includes physical activity participation. Results indicated that there is a low positive relationship between inactive participation and academic performance. However, there is a moderate positive relationship between minimally active participation and academic performance. Furthermore, there is a moderate positive relationship between HEPA active participation and academic performance. Related to the approach of relationship between physical activity participation and academic performance.
\end{abstract}

Keywords: Physical Activity Participation, Academic Performance

\section{Introduction}

Opportunity for participating in physical activity has been limited for everyone especially during this COVID-19 pandemic. Everyone was affected and restricted to participate in physical activity. (United Nations, 2020). This especially includes the students. Growing academic standards have also affected the time spent in engagement of physical activity. This possibly affects other elements such as student well-being and health. However, the amount of obesity and overweight problems were also increased as their physical activity participation decreased. In fact, this will lead to low motivation and self-esteem of the student. (Ying, 2017).

Physical activity participation and levels in physical activity were shown to be arbitration with the greater academic performance among the students (En Chung, 2018). Through this study, educators and students might be able to know whether or not physical education is required at nowadays academic institutions in any of the courses that students take. Another explanation for this study was to encourage healthier lifestyle students, because it is a fact that students are now only managing to finish their time on the screen, 
making no movement possible, especially during the COVID-19 pandemic. Surely, the outcomes of this research will illustrate the positive effects of physical activity participation and suggest whether there was a relationship between student participation in physical activity and their academic performance.

The relationship between physical activity participation and academic performance had gained exposure due to a rise in the incidence of chronic disease among adolescents and adults at a young age. Physical activity participation is very crucial for a variety of factors. It lessens the health consequences and thus prevents long-term conditions at risk of obesity and overweight among adults. Being active impacts learning, attention, and behaviours (Frank et. al., 2012). Research showed that physical health assessments were positively linked to academic achievement in educational contexts (Erin et. al., 2012). It is argued that school system administrators intend to do that while eliminating physical activity participation in the expectation of enhancing student academic performance in the fields of a variety of subjects. (Kibbe, 2011). A current trend amongst young adults is a sedentary lifestyle that leads to a lack of motivation, focus, and behavioral issues in class.

As the concept of removing physical education persists, many educators make the point that when realizing that physical activity is needed for students' growth and academic activities, they perceive it to be a big concern, enrichment or injustice, specifically if the academic institution goal was to improve poor academic performance. (Katherine, 2016). If there are a variety of good effects linked to socially involved and physically active, their impact there is little clarification about cognition and academic performance (Joseph, 2016). The purpose of the research is to look at the effect of physical activity participation towards the academic performance of UiTM Seremban 3 Students.

The purpose of this study is to expose the relationship between physical activity participation and academic performance among students. Study would also promote the promotion of sport, recreational, respectively and fitness at university, and continued fitness activities. Some evidence supports the fact that physical activity is an integral aspect of the educational steps and must be half of the program. (Kibbe, 2011). Based on what has already been said above, students are now just finishing their time on gadgets and mobile devices. This type of unhealthy lifestyle needs changing, but each form which can be transformed would be through the creation of healthy behaviours during the physical education class. (Mae, 2020).

The findings of this research will help identify how physical activity will enhance the total academic performance of students. The focus of this research will be to broaden the relationship between physical activity participation and academic performance. Educational institute officials, admin department, teachers, and parents need to comfort that physical activity needs to be applied in the course, and students are able to participate and not sit in the classroom to prepare for the syllabus exams (Joseph, 2016).

\section{Literature Review}

Over the years, physical activity, dependent on the practice of research and competition, has concentrated on cultivating the entire person as well as on raising the standard of living and well-being of those included. The mission and promotion increased by physical training experts is to ensure that students are engaging in daily physical activity so that students can experience positive effects for coming years.

Having a healthy body will also influence cognitive growth, and better health contributes to a better mental health. (WHO, 2000). Recent findings have shown us that 
bodies and brains are also not similar units, and that the acts lead to the brain capacity of the mental. (Glattfelder, 2019). It is believed that there will be less reduction in cognitive function and brain decay with frequent participation in physical activity even during especially in the mid days of life. (Laura, 2018). Have proposed that a goal of a physical activity program should be to give a student with experiences that may have an effect on their performance. (Kibbe, 2011). He also added that the physical activity will help make the student a better member of the community. Physical activity can eventually enhance somebody's standard of living by the delivery of quality, mental and emotional effects.

Students who are physically involved in long duration exercise have a greater level of achievement in mathematics than other academic fields. Strength training activities have been related to brain functions, pace reaction, cognitive memory and focus. (Fabian Herold, 2019). Several researches have demonstrated maximum levels of physical activity. Exercise had good effects on performance in mathematics and that there was no negative effect on increasing the amount of physical activity time on students. (Kibbe, 2011). The intensity of exercise has an impact on the academic success rate by contrasting intense workouts, moderate exercises and exercises among each other. (Bellarin, 2016). Strength training exercise can increase the heart rate higher than exercise enhancement. Intense exercises improve the mind and form of progressive and have a beneficial effect on males and females. (Parker, 2016).

Many that are involved feel a decrease in reduced lipids and time complexity lipoproteins. (Kenneth et. al, 2021). Physical activity also raises the volume of hormones. Enhance optimistic feelings. (Matthew, 2015). The effects of exercise on the brain and body go further in academic performance and worth to the well-being of an individual. As health improves, an environment of accomplishment and progress will begin to emerge. These neurotransmitters help improve the ability to concentrate of individuals, as well as raise moods, which can enhance the knowledge and skills.

Beliefs that exercise enhances this process, while at the same time creating communications among nerve cells in reaction to education and mental functions, known as perspective synaptic activity. (Kibbe, 2011). Then, neural activity is significant because it stimulates the higher the brain activity in the brain that are important for tracking, managing, and strategizing higher cognitive abilities that improve academic success. There are many brain steps that occur while participating in physical activity, and the more students are leading to these tasks, the more these functions will begin to be raised.

When academic duration decreased by physical activity and sports involvement to analyze the effects of increased physical activity and sports involvement. Findings also identified less disciplinary issues, decreased absenteeism, and increased focus. (Lundvall, 2015). Latest research from some countries have shown a similar view of standardized academic achievement as physical activity increased. As has been stated by (Barbosa, 2020) the physical level of youth has been on the decrease due in view to the reducing the amount of duration spent in the physical activity curriculum, rest and extracurricular. Most of these services have fallen into financial restrictions, although others have been discarded or modified by the admin department in the interest of academic transparency. Study does not endorse a reduction in physical activity time because of more time for academics. (Bellarin, 2016).

Therefore, three domains of category listed under the physical activity participation are inactive, minimally active and HEPA active. The inactive referred to no physical activity identified or only some sort of activity was reported but it was insufficient to meet the other 
domain. While, minimally active represents three or more days of vigorous activity in at least 20 minutes daily or five or more day participation in moderate physical activity or five days of any combination of walking or moderate or vigorous activity in minimum of at least $600 \mathrm{MET}-$ Min/Week. Lastly, HEPA active indicates vigorous physical activity at least three days with 1500 MET-Min/Week or seven days of walking, moderate or vigorous physical activity at minimum of 3000 MET-Min/Week. (IPAQ, 2004).

When students feel responsible for their personal wellbeing and become morally influenced to be physically healthy, that influence can be transferred to family and friends to healthier students in response. Physical education practitioners should take exercise instruction to cover the loss of physical activity participation of the students beyond the time. Exercise practices are above standard team sports experiences which are not always accessible, while exercise practices promote anyone's physical result. Students who take part in physical activities which will not only train themselves for fitness components, and will also cause students to enhance their metabolic rate and increase their cardiovascular wellbeing and mental ability during physical activity participation.

\section{Methodology}

The target population for this study was the Universiti Teknologi MARA (UiTM) Seremban Students. Which consists of estimates of 5000 students in total. This total number of students represent different faculties. As there are three faculties in this campus which is Faculty of Sports Science and Recreation (FSR), Faculty of Computer Science and Mathematics (FSKM) and also Faculty of Administrative Science and Policy Studies (FSPPP). (Universiti Teknologi MARA (UiTM) Kampus Seremban, 2020). The sample population is related to study focus on the analysis of the relationship between physical activity participation and academic performance.

The population is selected using Table Krejcie and Morgan, 1970. It is calculated based on a $5 \%$ margin of error with $95 \%$ confidence level. Alongside with a total 5000 number of population size and $50 \%$ of response distribution. The recommended sample size is 357 sample size. The Krejcie and Morgan, 1970 Table helps the researcher to determine the sample size. So, the researcher does not need to make the study on each of the samples. (Morgan, 1079).

The questionnaire used includes 2 sections: Section A and Section B. This International Physical Activity Questionnaire (IPAQ) reliability indicated good stability with Cronbach Alpha $(\alpha<80)$ typical IPAQ correlations about 0.80 reliability and it is good and stable enough to be distributed. A pilot study has been conducted towards 30 respondents in order to ensure reliability and validity of the questionnaire. This measure assesses the types of intensity of physical activity and sitting time that respondents do as part of their daily lives and is interpreted according to the IPAQ scoring protocol. Section A for the Demographic data consists of gender, race, age, education level and Cumulative Grade Point Average (CGPA). Section B of the form will be filled up with the physical activity participation. International Physical Activity Questionnaire (IPAQ) has been used to measure the physical activity participation of the respondents. There are 7 questions with 3 different domains in this section. The domains listed were inactive, minimally active and HEPA active. Respondents need to rate the day and time they spend in doing physical activity in the past 7 day duration. (IPAQ, 2004).

Data analysis in this research using IBM Statistical Package for Social Sciences (SPSS) 26.0 software in the process of analyzing the data that has been collected. The data were 
analyzed based on the objective. Objective will be analyzed using Spearman's Correlation Analysis because the data in findings was non-parametric type. Result shows significant value 0.10 which $p<0.05$, so that the data distribution was normal and the researcher used parametric statistical analysis.

\section{Findings}

This study was to find the relationship between physical activity participation and academic performance among Universiti Teknologi MARA (UiTM) Seremban Students. The objectives of the study are to observe the relationship between inactive participation and academic performance. To observe the relationship between minimally active participation and academic performance and to observe the relationship between HEPA active participation and academic performance. All the objectives listed were analyzed using Spearman's Correlation Analysis.

Table 1

Descriptive Statistics of Physical Activity Score

\begin{tabular}{llll}
\hline & & Frequency $(\mathrm{n})$ & Percentage $(\%)$ \\
\hline Physical & Inactive & 42 & 11.8 \\
Activity & Minimally Active & 55 & 15.4 \\
Score & HEPA Active & 260 & 72.8 \\
& Total & $\mathbf{3 5 7}$ & $\mathbf{1 0 0 . 0}$ \\
\hline
\end{tabular}

Table and figure above consists of descriptive statistics of analysis representing the respondent physical activity score. The table and figure illustrates that $42(11.8 \%)$ respondents were inactive in physical activity. While, there are also respondents who were minimally active in physical activity which represent 55 (15.4\%). Most of the respondents were HEPA Active. It shows 260 (72.8\%). The total respondents are 357.

Table 2

Relationship between Inactive Participation and Academic Performance

\begin{tabular}{llll}
\hline & $\mathbf{r}$ & $\mathbf{p}$ & $\mathbf{n}$ \\
\hline Inactive & .422 & .001 & 357 \\
Academic Performance & .422 & .001 & 357 \\
\hline
\end{tabular}

$* p<0.01$

Table 2 shows the correlation between inactive participation and academic performance. The results indicate low positive correlation between inactive and academic performance $(r=.422, p<0.01)$. However, the result shows significant correlation. Hence, hypothesis 1 is supported. This shows that the lower participation in physical activity indicates lower level of academic performance achieved among the students.

Table 3

Relationship between Minimally Active and Academic Performance

\begin{tabular}{llll}
\hline & $\mathbf{r}$ & $\mathbf{p}$ & $\mathbf{n}$ \\
\hline Minimally Active & .503 & .000 & 357 \\
Academic Performance & .503 & .000 & 357 \\
\hline
\end{tabular}

$* p<0.01$ 
The table represents the relationship between minimally active participation and academic performance. The correlation above shows moderate positive correlation $(r=.503$, $p<0.01$ ). Even so, the correlation stated was significant. Hypothesis 2 is supported. Where there is a positive relationship on minimally active participation with academic performance.

Table 4

Relationship between HEPA Active and Academic Performance

\begin{tabular}{llll}
\hline & $\mathbf{r}$ & $\mathbf{p}$ & $\mathbf{n}$ \\
\hline HEPA Active & .636 & .001 & 357 \\
Academic Performance & .636 & .001 & 357 \\
\hline
\end{tabular}

$* p<0.01$

Table 4 above shows the relationship between HEPA Active and academic performance. It shows that there was moderate positive correlation between HEPA Active and academic performance $(r=.636, p<0.01)$. However, the relationship represented is significant. This means that, the higher level of academic performance achieved the higher the participation in physical activity. Hypothesis 3 is supported. There is a positive relationship between HEPA Active participation and academic performance.

\section{Discussion}

This study aims to determine the relationship between physical activity participation and academic performance among UITM Seremban students. There are three objectives of this study. First one, to observe the relationship between inactive participation and academic performance. To observe the relationship between minimally active participation and academic performance. The third one is to observe the relationship between HEPA active participation and academic performance. From the demographic research findings, it has been shown that the respondents total in this research are 357, consisting of 168 males and 189 females from 21 until 41 years old who studied at UiTM Seremban in Diploma and Degree level education.

Based on research findings in table 2 that shows the relationship between inactive participation and academic performance. A passive participation in physical activity refers to people who participate least or not in any physical activity in their daily lives (New York State Department of Health, 2016). This may lead to risks such as developing high blood pressure where during studies it can stretch and damage student arteries. The resulting health problem can include vision and memory loss. Inactive participation may also lead to cognitive decline (Blaha, 2020). Besides, the table indicates 42 of the respondents were in the passive physical activity participation category. This means that these groups of students in UiTM Seremban have no engagement in any physical activity and this may lead to many health consequences mentioned above.

Furthermore, the findings in Table 3 show the relationship between minimally active participation and academic performance. According to (IPAQ 2004), minimally active were grouped into some criteria such as three or more days of vigorous activity at least 20 minutes or five day moderate or at least 30 minutes of walking daily. However, results show 55 students were minimally active. There are some good benefits to being minimally active as it changes the brain to protect memories and thinking skills among the students (Godman, 2014). Besides, minimal participation in physical activity indirectly enhances mood, sleep, reduces stress and anxiety, where all of those consequences may lead to cognitive impairment. 
Research findings in table 4 indicate the relationship between HEPA active participation and academic performance. Based on table 1, in total 260 respondents were in the HEPA active category. HEPA actively stands for Health-Enhancing Physical Activity. During physical activity participation, the heart pumps more oxygen to the brain and cognitive function. High intensity participation in physical activity is linked to improved academic performance and brain functions in the learning process. Vigorous physical activity participation is related to improved academic performance as it has been linked with better scores on academic tests, improved focus, and more efficient transfers of information from short to long term memory (Rubis, 2020).

\section{Conclusion}

Research results and findings show that physical activity participation positively affects the academic performance among UiTM Seremban students. However, the research found that the more active the student is in physical activity in their daily life or number of times in a week, is positively related to higher academic performance achievement as discussed in earlier findings and discussions. It is also not shown that participating in physical activity negatively impacts the UiTM Seremban student academic performance. But it shows that inactive participation in physical activity may lead to other health consequences which affect blood pressure.

Research associated with the study of physical activity participation and academic performance among students would be more beneficial if the sample size of participants is greater and involves more domain and elements such as the student self-reported measure. As suggested, their involvement in sports and physical fitness. Academic performance records such as Cumulative Grade Point Average (CGPA) that had been used in this research were accurate to measure the student academic performance.

\section{References}

Ana Barbosa, S. W. (2020). Physical Activity and Academic Achievement: An Umbrella Review. Bellarin, M. M. (2016). The Effect of Physical Activity and Exercise on the Academic Achievement of Elementary Students.

Blaha, R. S. (2020). High Blood Pressure: Prevention, Treatment and Research. Health. Retrieved from https://www.hopkinsmedicine.org/health/conditions-anddiseases/high-blood-pressure-hypertension/high-blood-pressure-preventiontreatment-andresearch\#: :text=But\%20when\%20the\%20pressure\%20is,memory\%20loss\%20and\% 20cognitive\%20decline.

En Chung, S. A. (2018). The Relationship between Levels of Physical Activity and Academic Achievement among Medical and Health Sciences Students at Cyberjaya University College of Medical Sciences.

Howie, E. K. R. R. (2012). Physical Activity and Academic Achievement in Children: A historical perspective. Journal of Sport and Health Science, 160-169. doi:10.1016/j.jshs.2012.09.003

Herold, F. A. T. (2019). Functional and/or structural brain changes in response to resistance exercises and resistance training lead to cognitive improvements - a systematic review.

Booth, F. W. C. K. (2012). Lack of Exercise is a Major Cause of Chronic Disease. 
Godman, H. (2014). Regular exercise changes the brain to improve memory, thinking skills. Health Publishing. Retrieved from https://www.health.harvard.edu/blog/regularexercise-changes-brain-improve-memory-thinking-skills-201404097110

International Physical Activity Questionnaire (IPAQ) Group. (n.d.). International Physical Activity Questionnaire (IPAQ).

Tamanal, J. M. C. H. (2020). Promoting Healthy Lifestyle in High School Students: Determination of the Lifestyle Status through the Healthy Lifestyle Screen (HLS) Assessment. Journal of Lifestyle Medicine.

Joseph, E., Donnelly, C. H.-R. (2017). Physical Activity, Fitness, Cognitive Function and Academic Achievement in Children: A systematic review. Sports Exercise. doi: https://dx.doi.org/10.1249\%2FMSS.0000000000000901

Katherine, B., Owen, P. P. (2016). Physical Activity and School Engagement in Youth: A Systematic Review and Meta Analysis. Educational Psychologist. doi:10.1080/00461520.2016.1151793

Kibbe, H. K. (2011). Physical Activity, Fitness and Physical Education: Effects on Academic Performance. 43-50.

Kenneth, R. F. M. (2021). Introduction to Lipids and Lipoproteins.

Lundvall, S. (2015). Physical Literacy in the Field of Physical Education. Journal of Sport and Health Science. doi: 10.1016/j.jshs.2015.02.001

Matthew, A. S.-K. R. (2015). The Effects of Stress on Physical Activity and Exercise.

Morgan, K. A. (1079). Sampling Table.

New York State Department of Health. (2016). Physical Inactivity and Cardiovascular Disease. Health. Retrieved from https://www.health.ny.gov/diseases/chronic/cvd.htm

Parker, W. R. (2016). Is There a Relationship Between Physical Fitness and Student Academic Achievement?

Rubis, D. (2020). Physical Activity to Help Students Perform Better in the Classroom. Health and Physical Education. Retrieved from https://nwcommons.nwciowa.edu/education_masters?utm_source=nwcommons.n wciowa.edu\%2Feducation_masters\%2F245\&utm_medium=PDF\&utm_campaign=PD FCoverPages

United Nations (UN). (2020). The impact of COVID-19 on sport, physical activity and well-being and its effect in social development. Social Inclusion. Retrieved from https://www.un.org/development/desa/dspd/2020/05/covid-19-sport/

Universiti Teknologi Mara (UiTM) Kampus Seremban. (n.d.).

Chan, Y. Y. K. K. (2017). Physical activity and overweight/obesity among Malaysian adults: findings from the 2015 National Health and morbidity survey (NHMS). Public Health. doi: https://doi.org/10.1186/s12889-017-4772-z 